Original Article

\title{
Effects of Magnesium Sulfate Therapy on GCS Scores in Patients with Severe Traumatic Brain Injury
}

\author{
Kazim Ali ${ }^{1}$, Muhammad Irfan ${ }^{1}$, Rabia Abbas ${ }^{2}$ \\ ${ }^{1}$ Department of Neurosurgery, Punjab Institute of Neurosciences (PINS), Lahore Pakistan. \\ ${ }^{2}$ Department of Hematology, Shaikh Zayed Hospital, Lahore, Pakistan.
}

\begin{abstract}
Objective: Traumatic brain injury (TBI) is the number one cause of death under 44 years of age; in spite of this fact, there is no standard available pharmacological agent for the treatment of brain injury. We evaluated the effectiveness of magnesium sulfate treatment for the management and outcome of TBI.

Material and Methods: The prospective cases $(n=60)$ of $T B I$ were included with non-probability consecutive sampling. They received standard protocol treatment for TBI and magnesium sulfate as an add on therapy. GCS was noted on two occasions, at the time of admission and on the 3rd day. T-test was used to compare the results and for identification of significance/insignificance results.

Results: Mean age of the patients was $37.12 \pm 13.25$ years. Majority were male (68.3\%), while females were $31.7 \%$. Mean duration of an elapsed post traumatic brain injury was $5.06 \pm 2.32$ hours. Mean GCS before magnesium sulfate treatment (on admission) was $5.46 \pm 1.521$; mean Glasgow coma (GCS) after magnesium sulfate treatment (on $3^{\text {rd }}$ day) was $8.03 \pm 2.56$. There existed a significant difference between the GCS scores at the time of admission and on $3^{\text {rd }}$ day ( $p$ value $<0.0001$ ). Mean GCS was $7.69 \pm 2.55$ in age < 30 years and it was $8.29 \pm 2.57$ in age $>30$ years, but this difference was not statistically significant. Similarly, the difference was not significant in the GCS with respect to gender and duration of disease.
\end{abstract}

Conclusion: A significant improvement was found in the GCS after magnesium sulfate therapy in patients with TBI.

Keywords: Glasgow Outcome Score (GCS), Traumatic Brain Injury (TBI), Magnesium Sulfate.

Corresponding Author: Kazim Ali

Punjab Institute of Neurosciences (PINS), Lahore

Email: doctorkazimali@hotmail.com

Date of Submission: 20-10-2020

Date of Revision: 02-12-2020

Date of Online Publishing: 25-12-2020

Date of Print: 30-12-2020

DOI: $10.36552 / p j n s . v 24 i 4.497$

\section{INTRODUCTION}

An outside force to the head cause CNS damage occurs in the form of traumatic brain injury (TBI) and its dysfunction. Different scales are used to quantify the head injury; the most common among them is the Glasgow Coma Scale (GCS) score. ${ }^{1}$ Injury to the brain is one of the major cause of deaths and morbidity across the world; 
especially among the individuals whose age is below 44 years. Head injury can cause memory loss, weakness of limbs, unconsciousness, coma and death. The most commonly affected age group is between 27 to 60 years. $^{2}$

The leading cause of head injury is motor vehicle related accidents, fall from height and work related injuries. ${ }^{3}$ Despite of all these facts and data, there is no recommended, standard pharmacological agent as a therapy for TBI. Medical management is the requirement for prevention of secondary brain injury. ${ }^{4}$ During the initial phase of TBI the excitotoxic events in the brain results in neuronal cell death. ${ }^{5}$ Various researches have been done but still no effective treatment is available to stop this cycle of excitotoxicity which leads to cell death. ${ }^{6}$

Various researches have shown the neuroprotective agent for the CNS. In one study, there was significant improvement in GCS after magnesium sulfate therapy. ${ }^{7}$ In another research, the head injury patients received magnesium sulfate bolus dose of fifty $\mathrm{mg} / \mathrm{kg}$ body weight after that every six hourly patients were given fifty $\mathrm{mg} / \mathrm{kg} \mathrm{MgSO} 4$ for twenty four hours. The effects of the treatment were assessed with Glasgow Coma Scale (GCS) score and motor function scores which were followed till two months post treatment. There was obvious significant improvement in the GCS score after two months (statistically significant $p=0.03$ ). Data from many studies have shown that after severe brain injury the free magnesium levels in the brain fall around fifty percent in the initial hours. Outcome of the patients improved when magnesium levels were brought upto the normal baseline levels with the use of various pharmacological approaches. ${ }^{8-9}$

One study (randomized control trial) showed improvement in GCS (on the third day) and GOS with magnesium sulfate therapy as compared to the control group in which only standard treatment was given without magnesium. Data from recent meta-analysis of existing randomized controlled trials show that magnesium sulfate has a role in improving the GCS and GOS scores. ${ }^{8-9-10}$

Mechanism of magnesium has been studied in different animal researches; it has a neuro protective action by blocking the NMDA and calcium channel receptors along with that it inhibits the excitatory neurotransmitter release. ${ }^{12-}$ 14 The purpose of the study was to determine mean GCS in patients with head injury after magnesium sulfate therapy. Also to see the short and long term effects of magnesium on the outcome of patients. This study can add useful data which can be utilized for the betterment of the patients. Results were compared with international studies available.

\section{MATERIALS AND METHODS}

\section{Study Setting and Sampling}

A prospective case series study was conducted in the Department of Neurosurgery at Shaikh Zayed Hospital (SZH), Lahore from May 2018 to July 2019. We enrolled 60 patients who presented with traumatic brain injury (TBI). Written Informed consents were taken from all patients or from the attendantsas per institutional ethical standards.

Patients were selected on the basis of nonprobability consecutive sampling. Patients background information and clinical presentations were recorded. Patients were evaluated consisting of a detailed history, physical examination (history of loss of consciousness, ENT bleed, fits, vomiting, anterograde and retrograde amnesia).

\section{Inclusion Criteria}

We included patients of both genders with traumatic brain injury with age between $18-70$ years who gave consent.

\section{Exclusion Criteria}

We excluded pregnant women, children less than 18 years of age, patients with poly trauma, 
patients with significant metabolic diseases (chronic kidney disease, ischemic heart disease, cardiac failure) and those patients who did not give consent.

\section{Clinical Information}

All patients had undergone a CT scan (brain plain). Baseline investigations, including complete blood count, coagulation profile, LFTs, RFTs and other relevant investigations were done as preoperative workup. TBI patients were given standard treatment (patient were managed according to brain trauma guidelines, nasogastric/Foleys passed, intravenous fluids, Mannitol infusion, antibiotics, nutrition, antiepileptic as required, surgery if indicated) plus magnesium sulfate.

\section{Treatments of TBI}

The regular mode of treatment for TBI was that they received standard protocol treatment (patient is managed according to brain trauma guidelines, NG/Foleys passed, intravenous fluids, Mannitol infusion, antibiotics, nutrition, antiepileptic as required, surgery if indicated) and along with this patients were given magnesium sulfate as an add on therapy. Treatment guidelines consisted of an initial loading dose of
$50 \mathrm{mg} / \mathrm{kg}$ magnesium sulfate and then $15 \mathrm{mg} / \mathrm{kg}$ T.D.S up to 48 hours after the trauma. GCS score and serum magnesium levels were noted on two occasions, at the time of admission and on the 3rd day.

\section{Data Analysis}

Data analysis was performed in SPSS (v.22.0, IBM Corporation) software. All the variables, includingsocial, demographic data like name, age, sex and address was collected. The clinical outcome was evaluated by using GCS (on admission and at $3^{\text {rd }}$ day). Categorical variables like gender was described as frequencies and percentages. Quantitative variables like age, weight, height, was described as mean +/standard deviation. The continuous variable like serum Magnesium levels and age was presented in the form of mean and S.D. Qualitative variable like gender and grades of Glasgow Coma Scale, was presented in the form of frequency and percentages. Data was stratified by age and gender with regard to outcome variable, i.e. Glasgow coma scale score. T test was used to compare the results and for identification of significance/insignificance results. A $p$ value $\leq 0.05$ was considered as significant.
Table 1: Mean Glasgow Coma Score before and after magnesium sulfate treatment.

\begin{tabular}{llll} 
& Condition & Mean \pm SD & p Value \\
Glasgow & Before Magnesium sulfate & $5.46 \pm$ & 0.0001 (highly \\
coma scale & treatment (on admission) & 1.521 & significant) \\
(GCS) & $\begin{array}{l}\text { After Magnesium sulfate } \\
\text { treatment (on 3rd day) }\end{array}$ & $8.03 \pm 2.56$ & T test: $6.7213 ;$ \\
& & & df: 118 \\
\hline
\end{tabular}

Table 2: Glasgow Coma score with respect to age.

\begin{tabular}{|lccc|} 
& Age Category & Mean \pm SD & p-value \\
Glasgow Coma & $18-30$ years & $7.69 \pm 2.55$ & \\
Score & $>30$ years & $8.29 \pm 2.57$ & 0.37 \\
\hline
\end{tabular}

\section{RESULTS}

\section{Age Incidence}

The mean age of the study participants was $37.12 \pm 13.25$ years.

\section{Gender Distribution}

Main component of the patients were male $41(68.3 \%)$ while few were female 19 (31.7\%).

The mean duration of an elapsed post traumatic brain injury was $5.06 \pm$ 2.32 hours. 


\section{Compassions of Glasgow Coma Score (GCS)}

Mean GCS before magnesium sulfate treatment (on admission) was $5.46 \pm 1$. 521; mean Glasgow coma (GCS) after magnesium sulfate treatment (on the 3rd day) was $8.03 \pm 2.56$. There existed a significant difference between the GCS scores at the time of admission and on the 3rd day ( $p$ value < 0.0001) (Table 1). In this study, it is noted that the mean Glasgow coma score was 7. $69 \pm 2.55$ at age $<30$ years and it was $8.29 \pm 2.57$ in age group $>30$ years, but the difference was not statistically significant (Table 2). Similarly, there was no significant difference in the Glasgow coma score with respect to gender and duration of disease (Tables 3-4).

\section{DISCUSSION}

This research provides a data on the effectiveness of magnesium sulfate treatment in the patients with traumatic head injury. In this study, both GCS scores before magnesium sulfate treatment (on admission) and after magnesium sulfate treatment (on the 3rd day) were compared. Results clearly show a significant improvement in the GCS after magnesium sulfate treatment. There is a need to do human trials to see the effectiveness and safety profile of magnesium levels in the CSF. ${ }^{15}$ One randomized controlled trial provided a data on the effectiveness of five days magnesium therapy by assessing the GCS and GOS scores in patients. They compared the results with a control group, which received only standard therapy for traumatic brain injury without magnesium sulfate. ${ }^{16}$

In a study, it was found that the I/V infusion of magnesium sulfate only slightly increases the levels in CSF. ${ }^{17}$

We need to find out whether this minimal increase in magnesium sulfate levels will raise the cellular concentration of free magnesium which is neuro-protective. ${ }^{18}$ Levels of magnesium in CNS depend on the integrity of the blood brain barrier.Trauma in animals damages the blood brain barrier which results in increase magnesium concentration in the cell for twenty four hours, this doesn't happen in human CNS. ${ }^{19}$

Neuronal cell death after brain injury has multiple factors that are why combination therapy is recommended in many reports. Combination therapies target more than one factor, and they have gained attention over the period of time and have more efficacy. Various combination therapies have been studied in patients with brain injury like magnesium in combination with growth factors, glutamate antagonists, vitamin $B$, immunosuppressant, hypothermia, antioxidants. Combination therapy of magnesium and hypothermia gave better results on the outcome of head injury patients. More studies need to be done to see the effectiveness of combination therapy of magnesium and hypothermia. ${ }^{20}$ This research showed that magnesium sulfate improves the GCS score of brain injury patients and ultimately the outcome. Further studies need to done to generalize the results so that patients can benefit from the add on therapy of magnesium sulfate. 


\section{CONCLUSION}

A significant improvement was noted in GCS after magnesium sulfate therapy in patients with TBI. Itis recommended for abetter outcome of patients with TBI. However, more studies need to be done for the generalizability of the results.

\section{REFERENCES}

1. Senathi-Raja D, Ponsford J, Schönberger M. Impact of age on long-term cognitive function after traumatic brain injury. Neuropsychology, 2010; 24 (3): 336.

2. Mosenthal AC, Lavery RF, Addis M, Kaul S, Ross S, Marburger $\mathrm{R}$, Deitch EA, Livingston $\mathrm{DH}$. Isolated traumatic brain injury: age is an independent predictor of mortality and early outcome. Journal of Trauma and Acute Care Surgery, 2002; 52 (5): 907-11.

3. Rapoport MJ, Feinstein A. Outcome following traumatic brain injury in the elderly: a critical review. Brain Injury, 2000; 14 (8): 749-61.

4. Li W, Bai YA, Li YJ, Liu KG, Wang MD, Xu GZ, Shang $\mathrm{HL}$, Li YF. Magnesium sulfate for acute traumatic brain injury. J Craniofac Surg. 2015; 26 (2): 393-8.

5. Busingye DS, Turner RJ, Vink R. Combined Magnesium/Polyethylene Glycol Facilitates the Neuroprotective effects of magnesium in traumatic brain injury at a reduced magnesium dose. CNS Neuroscience \& Therapeutics, 2016; 22: 854-859.

6. Herrera-Melero MC, Egea-Guerrero JJ, VilchesArenas A, Rincón-Ferrari MD, Flores-Cordero JM, León-Carrión J, Murillo-Cabezas F. Acute predictors for mortality after severe TBI in Spain: Gender differences and clinical data. Brain Injury, 2015; 29 (12): 1439-44.

7. Zhao L, Wang W, Zhong J, Li YY, Cheng YZ, Su Z, et al. The effects of magnesium sulfate therapy after severe diffuse axonal injury. Ther Clin Risk Manag. 2016; 12: 1481-1486.

8. Haring RS, Narang K, Canner JK, et al. Traumatic brain injury in the elderly: morbidity and mortality trends and risk factors. J Surg Res. 2015; 10: 750 756.

9. Gennarelli TA, Thibault LE, Adams JH, Graham DI, Thompson CJ, Marcincin RP. Diffuse axonal injury and traumatic coma in the primate. Annals of
Neurology: Official Journal of the American Neurological Association and the Child Neurology Society, 1982; 12 (6): 564-74.

10. Mac Donald $C L$, Johnson AM, Cooper D, Nelson EC, Werner NJ, Shimony JS, et al. Detection of blast-related traumatic brain injury in U.S. military personnel. N Engl J Med. 2011; (22): 2091-100.

11. Tian $H L$, Geng $Z$, Cui $Y H$, et al. Risk factors for posttraumatic cerebral infarction in patients with moderate or severe head trauma. Neurosurg Rev. 2008; 12: 800-806.

12. McKee AC, Cantu RC, Nowinski CJ, et al. Chronic traumatic encephalopathy in athletes: progressive tauopathy after repetitive head injury. J Neuropathol Exp Neurol. 2009; 68 (7): 709-35.

13. Powell JM, Ferraro JV, Dikmen SS, Temkin NR, Bell KR. Accuracy of mild traumatic brain injury diagnosis. Archives of physical medicine and rehabilitation, 2008; 89 (8): 1550-5.

14. Seel RT, Macciocchi S, Kreutzer JS. Clinical considerations for the diagnosis of major depression after moderate to severe TBI. The Journal of Head Trauma Rehabilitation, 2010; 25 (2): 99-112.

15. Coronado VG, Thomas KE, Sattin RW, Johnson RL. The CDC traumatic brain injury surveillance system: characteristics of persons aged 65 years and older hospitalized with a TBI. The Journal of Head Trauma Rehabilitation, 2005; 20 (3): 215-28.

16. Boake C, McCauley SR, Levin HS, Pedroza C, Contant CF, Song JX, Brown SA, Goodman H, Brundage SI, Diaz-Marchan PJ. Diagnostic criteria for postconcussional syndrome after mild to moderate traumatic brain injury. The Journal of Neuropsychiatry and Clinical Neurosciences, 2005; 17 (3): 350-6.

17. Dutca LM, Stasheff SF, Hedberg-Buenz A, Rudd DS, Batra N, Blodi FR, Yorek MS, Yin T, Shankar M, Herlein JA, Naidoo J. Early detection of subclinical visual damage after blast-mediated TBI enables prevention of chronic visual deficit by treatment with P7C3-S243. Investigative Ophthalmology \& Visual Science, 2014; 55 (12): 8330-41.

18. Cassidy JD, Carroll L, Peloso P, Borg J, Von Holst H, Holm L, Kraus J, Coronado V. Incidence, risk factors and prevention of mild traumatic brain injury: results of the WHO Collaborating Centre Task Force on Mild Traumatic Brain Injury. Journal of 
Rehabilitation Medicine, 2004; 36 (0): 28-60.

19. Hahn RA, Bilukha $O$, Crosby $A$, et al. "Firearms laws and the reduction of violence: a systematic review". Am J Prev Med. 2005; 28 (2): 40-71.
20. Wang, F.; Wang, Y.; Sun, T.; Yu, HL. "Hyperbaric oxygen therapy for the treatment of traumatic brain injury: a meta-analysis". Neurol Sci. 2016; 37 (5): 693-701.

\section{Additional Information}

Disclosures: Authors report no conflict of interest.

Ethical Review Board Approval: The study was conformed to the ethical review board requirements.

Human Subjects: Consent was obtained by all patients/participants in this study.

\section{Conflicts of Interest:}

In compliance with the ICMJE uniform disclosure form, all authors declare the following:

Financial Relationships: All authors have declared that they have no financial relationships at present or within the previous three years with any organizations that might have an interest in the submitted work.

Other Relationships: All authors have declared that there are no other relationships or activities that could appear to have influenced the submitted work.

\section{AUTHORS CONTRIBUTIONS}

\begin{tabular}{|l|l|l|}
\hline Sr.\# & Author's Full Name & Intellectual Contribution to Paper in Terms of: \\
\hline 1. & Kazim Ali & Study design, methodology, data calculations and paper writing \\
\hline 2 & Rabia Abbas & Analysis of data and interpretation of results. \\
\hline 3. & Muhammad Irfan & Literature review and manuscript writing. \\
\hline
\end{tabular}

